\title{
Studies of Permeability Changes and Mass Transfer in Carbonate Rocks
}

\author{
A.V. Lekhov \\ Hydrogeology Section, Department of Geology \\ Moscow State University, Moscow, 119899, Russia
}

September 1996

Russian-American Center for Contaminant Transport Studies

Earth Sciences Division

Ernest Orlando Lawrence Berkeley National Laboratory

University of Califormia

Berkeley, California 94720

The preparation of this report was supported by the Department of Energy, Office of Energy Research, Office of Basic Energy Sciences (DOE/ER-BES) Engineering and Geosciences Division, under Contract Number DE-AC0376 SF00098. 


\section{DISCLAIMER}

This report was prepared as an account of work sponsored by an agency of the United States Government. Neither the United States Government nor any agency thereof, nor any of their employees, make any warranty, express or implied, or assumes any legal liability or responsibility for the accuracy, completeness, or usefulness of any information, apparatus, product, or process disclosed, or represents that its use would not infringe privately owned rights. Reference herein to any specific commercial product, process, or service by trade name, trademark, manufacturer, or otherwise does not necessarily constitute or imply its endorsement, recommendation, or favoring by the United States Government or any agency thereof. The views and opinions of authors expressed herein do not necessarily state or reflect those of the United States Government or any agency thereof. 


\section{DISCLAIMER}

\section{Portions of this document may be illegible in electronic image products. Images are produced from the best available original document.}




\begin{abstract}
The paper describes a number of studies of permeability changes and mass transfer in carbonate rock. These studies are presented along three lines: (a) a theoretical study of karstification, (b) karstic structure of a carbonate rock mass, and (c) processes of mass transfer in a carbonate rock aquifer.
\end{abstract}




\section{Introduction}

The permeability of carbonate rocks is always connected with karstification. Carbonate rocks occupy more than $35 \%$ of the surface of the earth. More than $50 \%$ of the European part of Russia and Ukraine, including the Ural Mountains, is made up of carbonate rocks. France and Yugoslavia have large territories of carbonate rocks. The name "karst" originated from the name of a mountain plate in Yugoslavia. Karst occurs widely in Mexico, and Cuba. In the U.S., karstic rocks occur in the Appalachian mountains. Florida has a principal aquifer in carbonate rocks. Sometimes carbonate rocks occupy only a small territory of a country, but they are the basic source of that country's water supply, for example in Kazakhstan.

Carbonate rocks play an important role in water supply. In a number of regions the majority of the population lives in areas underlain by carbonate rocks. Though well known as basic aquifers for drinking water supply, in many regions carbonate rocks are present to depths of hundreds of meters and can therefore also be places for disposal of liquid industrial wastes.

In this work, I attempt to present a number of theoretically based hydrogeological research, whose results can be used in forecasts of the quantity of water pumped from wellfields, speed of transport, and concentration of pollution.

There are two possible directions in the theoretical investigations of karstification:

1. The main direction (as discussed above) includes analysis of karstic forms' distribution and their relationship with the geological structure of massifs, resulting in generation of permeability structure based on statistical analysis.

2. Another direction includes synthesis of process models at different scales of massifs' structures, resulting in generation of permeability structure by a method of hydrogeomigration modeling. (My research as presented below).

Naturally, there is an association between the two directions. 
The solution of all carbonate hydrogeological questions is based on the structure of the permeability of the aquifers. It defines the production of water from wells, prediction of pollution distribution, allocation of well filters, and distribution of wells for groundwater monitoring. The existing theories of karstification cannot explain many phenomena observable in field research.

For example:

- a greater drawdown of the groundwater level in distant observation wells than in nearby wells is frequently observed during pumping

- fast movement of contaminants is inconsistent with the common porosity of the aquifer.

- High permeability zones occur at depths of a few tens to hundreds meters.

The process of mass transfer in carbonate karstic massifs depends on karstic fractures. Large channels and caves seldom intersect and they occupy a very small amount of the total space of carbonate rocks massifs; therefore, they are not considered.

My research consists of three parts:

- Theoretical study of karstification;

- Karstic structure of a carbonate-rock massif;

- Processes of mass transfer in a carbonate rock aquifer.

\section{A Theoretical Study of Karstification}

\subsection{Reason of Limestone Dissolution}

Abundant experimental research of limestone dissolution kinetics shows a high rate of process. Ground water chemistries come in balance with calcite in the first centimeters of a migration pathway in the natural range of seepage velocities. Karst exists to depths of hundreds of meters in limestone massifs. Hence, there are the reasons for a disturbed balance of the hydrogeochemical system. The real massifs of limestones represent alternation of limestone layers with small changes of structure and chemical composition (limestone properties). 
Natural calcite represents a solid solution of calcium carbonate and carbonates of bivalent metals. Magnesium carbonate is the most abundant. The quantity of magnesium defines the solubility of calcite. In Figure 1.1 this phenomenon is shown. Calcite with a 3\% molar fraction of magnesium has minimum dissolution. The molar fraction of magnesium in limestones does not usually exceed 5\%. It is the first and main reason that the ground water in equilibrium with one calcite will not be in equilibrium with another calcite. The second reason is the structure of calcite. With the reduction of the sizes of crystals and the increase of the number of defects, there is an increase in calcite solubility. In Figure 1.1 the dependence of the solubility of calcite with grain size is shown. However, this phenomenon is less important than the change of the chemical composition of calcite.

Hence, small changes in a limestone composition and structure will determine whether the ground water in contact with layers will become undersaturated or oversaturated.

It is necessary to note that the composition of calcite precipitation is determined by the magnesium and calcium ratio in ground water as shown on Figure 1.1. Pure calcite will precipitate in massifs of carbonate rocks.

\subsection{Kinetics of Limestone Dissolution}

The model of kinetics of limestones dissolution for solutions which are more than $40 \%$ saturated with calcite can satisfactorily be described as an equation expressed in substance activities:

$$
\mathrm{R}=\mathrm{dC} / \mathrm{dt}=\left(\mathrm{k}_{\mathrm{f}}\left[\mathrm{H}^{+}\right]-\mathrm{k}_{\mathrm{b}}\left[\mathrm{Ca}^{2+}\right]\left[\mathrm{HCO}_{3}^{-}\right]\right) \mathrm{S} / \mathrm{V}
$$

where $V=$ volume of a solution, $S=$ area of a dissolution surface, $k_{f}$ and $k_{b}=$ constants of forward and back reactions rates, $[\mathrm{A}]=$ activity of substance $\mathrm{A}$. This equation is inconvenient for integration and analytical research.

The equivalent model for fresh ground waters which are more than $85 \%$ saturated in calcite in a natural range of partial pressure of carbon dioxide looks like first order equation:

$$
\mathrm{R}=\mathrm{dC} / \mathrm{dt}=\mathrm{k}\left(\mathrm{C}_{\mathrm{m}}-\mathrm{C}\right) \mathrm{S} / \mathrm{V} \text {; }
$$


where $\mathrm{C}$ and $\mathrm{C}_{\mathrm{m}}$ are the current and equilibrium concentrations of dissolved calcite respectively; $\mathrm{k}=$ the coefficient of dissolution rate. Using this equation gives an error less than 5\%.

The coefficient of dissolution rate depends on the contents of carbonic acid in solution, temperature, and pressure. Its value depends on whether the system is open or is closed to carbon dioxide, as is shown in Figure 1.2. For a system closed to carbon dioxide at temperature $5^{\circ} \mathrm{C}$, the value of the coefficient of dissolution rate is about $3 \cdot 10^{-5} \mathrm{~cm} / \mathrm{s}$ in fresh water.

Hence, in natural conditions on borders of limestone layers, the dissolution kinetics equation of the first order will pertain.

\subsection{Dissolution of Fracture Walls.}

The chink is the simple model for the description of percolation into, and dissolution of, walls of a fracture (Figure 1.3). We assume mass transfer on the axis of a fracture is by convection, and from walls to center by diffusion. The bidimension equation is:

$$
\mathrm{D} \frac{\partial^{2} \mathrm{C}}{\partial \mathrm{y}^{2}}=1.5 \mathrm{u}\left[1-(\mathrm{y} / \mathrm{b})^{2}\right] \frac{\partial \mathrm{C}}{\partial \mathrm{x}}
$$

where $D=$ diffusion coefficient, $u=$ average flow velocity $(u=q / b)$. The boundary conditions are:

$$
\begin{aligned}
& \mathrm{C}(0, \mathrm{y})=\mathrm{C}_{0} \quad ; \quad \partial \mathrm{C}(\mathrm{x}, 0) / \partial \mathrm{y}=0 ; \\
& \mathrm{D} \partial \mathrm{C}(\mathrm{x}, \mathrm{b}) / \partial \mathrm{y}=\mathrm{k}\left[\mathrm{C}_{\mathrm{m}}-\mathrm{C}(\mathrm{x}, \mathrm{b})\right] ;
\end{aligned}
$$

The solution of this problem is known. However it is inconvenient to use it for research of the behavior of a fracture and groups of fractures. The behavior of a fracture can be described in the monodimensional equation

$$
\mathrm{q} \partial \mathrm{C} / \partial \mathrm{x}=\alpha\left(\mathrm{c}_{\mathrm{m}}-\mathrm{C}\right) \Rightarrow \alpha=\frac{\mathrm{q} \partial \mathrm{C} / \partial \mathrm{x}}{\left(\mathrm{C}_{\mathrm{m}}-\mathrm{C}\right)} ;
$$

where $\mathrm{q}=\mathrm{ub}$ is solitary flow in a fracture, $\mathrm{b}$ is the distance from a fracture axis up to a wall (aperture), $\alpha$ is the coefficient of fracture mass exchange. 
The solution of the bidimensional equation enables us to define the mass exchange coefficient of a fracture of final length $\mathrm{x}$ :

$$
\mathrm{Sh}=\frac{\mathrm{ab}}{\mathrm{D}}=-\frac{2 \ln \overline{\mathrm{C}}}{3 \overline{\mathrm{x}}} ; \overline{\mathrm{x}}=\frac{2 \mathrm{Dx}}{3 \mathrm{ub}^{2}} \quad ; \quad \mathrm{C}=\frac{\mathrm{C}_{\mathrm{m}}-\mathrm{C}}{\mathrm{C}_{\mathrm{m}}-\mathrm{C}_{0}} .
$$

The behavior of the mass exchange coefficient is shown in Figure 1.3. From the following solution the mass exchange coefficient of fractures in the majority of natural conditions will be constant. The areas of natural conditions and laboratory experiments with chinks in limestones are shown in Figure 1.3.

In the field of constant values of the mass exchange coefficient there is the dependency $\mathrm{Sh}=$ $\mathrm{Sh}(\mathrm{Bi})$, where $\mathrm{Bi}=\mathrm{kb} / \mathrm{D}$. It is possible to allocate three regimes of dissolution of fractures' walls corresponding to three areas of determining parameters:

\section{Regime}

Kinetic $\quad \mathrm{Sh}=\mathrm{Bi}$ or $(\alpha=\mathrm{k})$;

Diffusive $\quad$ Sh $=$ const ;

Diffusive-kinetic $\quad \mathrm{Sh}=\mathrm{Sh}(\mathrm{Bi})$.

The analysis of experimental research of dissolution kinetics of calcite and the estimations of natural conditions show that in limestones practically all fractures with apertures less than 0.3 $\mathrm{cm}$ are dissolving in the kinetic regime.

\subsection{Change in Fracture Aperture from Dissolution of Walls}

The model of the change of aperture is simulated as

$$
q \frac{\partial C}{\partial x}+\frac{\partial(b C)}{\partial t}=\alpha\left(c_{m}-C\right)=\rho \frac{\partial b}{\partial t} ;
$$

where $\rho$ is the density of rock (limestone). The density of rock is much greater than the concentration of calcite dissolved in water $(\rho>>C)$. The Characteristic time of change in the fracture aperture is much greater than the water migration time from an entrance of a fracture to an exit. Hence, the equation is simplified: 


$$
q \frac{\partial C}{\partial x}=\alpha\left(C_{m}-C\right)=\rho \frac{\partial b}{\partial t}
$$

with boundary conditions

$$
\mathrm{C}(0, \mathrm{t})=\mathrm{C}_{0} \quad ; \mathrm{b}(\mathrm{x}, 0)=\mathrm{B}
$$

The solution at the constant discharge of water $(q=$ const $)$ is

$$
\begin{aligned}
& \overline{\mathrm{C}}=\exp (-\overline{\mathrm{x}}) ; \overline{\mathrm{b}}=\tau \exp (-\overline{\mathrm{x}})+1 ; \\
& \overline{\mathrm{x}}=\mathrm{kx} / \mathrm{q} ; \tau=\mathrm{kt}\left(\mathrm{C}_{\mathrm{m}}-\mathrm{C}\right) /(\mathrm{b} \rho) ; \overline{\mathrm{b}}=\mathrm{b} / \mathrm{B} .
\end{aligned}
$$

For a fracture of final length 1 it is possible to define its volume and permeability or characteristics of these sizes-average and effective apertures as

$$
\begin{aligned}
& \mathrm{b}_{\mathrm{av}}=\frac{1}{1} \int_{0}^{1} \mathrm{~b}(\mathrm{x}) \mathrm{dx} \quad ; \mathrm{b}_{\mathrm{ef}}^{3}=1\left[\int_{0}^{1} \mathrm{~b}^{-3}(\mathrm{x}) \mathrm{dx}\right]^{-1} ; \\
& \overline{\mathrm{b}_{\mathrm{av}}}=\tau[1-\exp (-\overline{\mathrm{l}})] / \overline{1} \neq 1 ; \\
& \overline{\mathrm{b}_{\mathrm{ef}}^{3}}=\overline{1}\left\{\ln \frac{\exp (\overline{\mathrm{l}})+\tau}{1+\tau}+\frac{\tau}{2}\left[\frac{4 \exp (1)+3}{[\exp (\overline{1})+\tau]^{2}}\right]\right\} .
\end{aligned}
$$

The dependencies of average and effective fracture apertures for varying times and lengths are shown in Figure 1.4.

\section{The Karstic Structure of a Carbonate Rock Massif}

\subsection{Karst Process in a Group of Parallel Fractures}

Practically all massifs of limestones have lamination. Three main perpendicular systems of fractures occur most frequently in layers of limestones. One system is parallel to the contact and the two others are perpendicular. Fracture apertures are originally distributed under the normal law, as has been shown in study of fractures over depths of a few thousand meters. 
The water passes through a surface of the contact layer and becomes deficient of saturation. In following a migration pathway the water dissolves walls of the fractures. The fractures that have greater aperture have greater flows of water. Hence, they are opening faster.

The total discharge of a fracture system, oriented in the direction of seepage velocity is defined as:

$$
\mathrm{Q}=\sum_{\mathrm{i}=1}^{\mathrm{I}} \mathrm{q}_{\mathrm{i}}=\mathrm{A} \sum_{\mathrm{i}=1}^{\mathrm{I}} \mathrm{b}_{\mathrm{ef}}^{3}=\mathrm{AI} \beta_{\mathrm{ef}}^{3}=\frac{1}{\mathrm{I}} \sum_{\mathrm{i}=1}^{\mathrm{I}} \mathrm{b}_{\mathrm{ef}}^{3} \quad ; \quad \mathrm{A}=\alpha \Delta \mathrm{H}
$$

where $\mathrm{I}$ is the quantity of fractures in aggregate; $\Delta \mathrm{H}$ the difference of heads on the ends of fractures; A the constant size for fractures of length 1.

We assume for modeling that the discharge for all groups of fractures $Q$ is constant. The individual discharges are distributed on fractures proportionally to their effective aperture. During modeling we calculate the integrated characteristics of a system undergoing changes of average porosity and permeability (first statistical moment), dispersion (second statistical moment) and symmetry (third statistical moment);

$$
\begin{aligned}
& \overline{b_{a v}}=\frac{1}{I} \sum_{i=1}^{I} b_{a_{i}} ; \overline{b_{a f}^{3}}=\frac{1}{I} \sum_{i=1}^{I} b_{e_{i}}^{3} \\
& \sigma_{a v}=\frac{1}{I} \sum_{i=1}^{I}\left(\overline{b_{a v}}-b_{a v_{i}}\right)^{2} ; \sigma_{e f}=\frac{1}{I} \sum_{i=1}^{I}\left(\overline{b_{a f}^{3}}-b_{e_{i}}^{3}\right)^{2} \\
& \mu_{a v}=\frac{1}{I} \sum_{i=1}^{I}\left(\overline{b_{a v}}-b_{a_{i}}\right)^{3} ; \mu_{e f}=\frac{1}{I} \sum\left(\overline{b_{a f}^{3}}-b_{e_{i}}^{3}\right)^{3} .
\end{aligned}
$$

As a result we obtain a temporary sequence of cumulative curves and three first statistical moments for average weighted and effective apertures, and also deficits of saturation at each fracture exit. The results are shown in Figure 2.1.a.

The waters from almost all fractures of the group leave saturated by dissolving the limestone, and are therefore deprived of further dissolution ability. Only in the case of the large discharges from he largest fracture are there waters with concentrations less than saturation, 
which therefore can dissolve fracture walls and expand them. Saturation by dissolving wall rock occurs in the majority of fractures in a rather small way (Figure 2.1.b).

The most characteristic feature of the karst process is the increase of one fracture of a group and inhibition in growth rates in others at major total discharges, and a rather uniform increase at the entrance areas of all fractures at small discharges. In the case of small discharges and insignificant dispersions, the initial distribution will occur as though to consume rocks at an entrance by dissolving rock by undersaturated ground waters. Any fracture has varying apertures. It is possible to assume that in each fracture, especially in large ones, similar processes will occur, resulting in development of roundish channels (Figure 2.1.c).

\subsection{Karstic Structure of a Limestones Massif}

The main places of change in percolation properties will be at surfaces of limestone layers. These surfaces have thin zones where increase or reduction of permeability depends on calcite dissolution or precipitation processes.

The thin zones of increased permeability represent a system of crossed channels or flat pipes. The originally large fractures will create a network of large pipes, which defines practically all transmissivity of the thin zone. The fracture with an originally smaller aperture will create a network of small flat pipes, connecting with the larger pipes. The provisional prospect of thin zones of increased permeability is shown on Figure 2.2.a.

The limestone aquifer represents a suite of thin zones of increased permeability. The zones are separated hydraulically. Separation is increased for some layer contact zones where permeability is reduced by precipitation of calcite.

The distribution of increased and lowered permeability zones in a massif with horizontal lamination depends mainly on changes in lithology of the limestones. The chemical composition of infiltration waters will be practically identical in the area. The scheme of arrangement of the zones is shown in Figure 2.2.b. 
The distribution of zones in a massif with inclined lamination is defined by the place of a pathline entrance. The water, moving on a pathline, enters reaction of dissolution or precipitation according to its initial chemical composition, which is determined by the composition of the limestone at the pathline starting place. The results of modeling of this arrangement are shown in Figure 2.2.c.

\subsection{Methods of Zones Detection by Field Experiments}

Good results were obtained by methods of well examination. The following parameters were measured along the well's axis:

- Inflow and diameter;

- Temperature;

- Electrical resistance.

The most successful is the flowmeter method. The other methods of geophysical measurements of wells do not give good results.

The flowmeter method is carried out as follows:

- Measurement of well diameters as a function of depth;

- Dynamic inflow measurement by moving the sensor with constant velocity downwards and upwards along a well and recording its signal (Figure 2.3).

- Determination of the location of thin zones of increased permeability and choice of convenient places of the inflow measurement with a step-by-step sensor movement.

On Figure 2.3 results of determination of the relative transmissivity of thin permeable zones in a limestone aquifer in the Moscow region are shown. Seven wells are located in an area 300 $\times 300$ sq. M near the Moscow river. Figure 2.3 also shows average values of relative transmissivity of the site. 


\section{Process of Mass Transfer in a Carbonate Aquifer}

\subsection{Coefficient of Transverse Hydrodynamic Dispersion in a Thin Permeable Zone}

A thin permeable zone can be considered as a bidimensional network of pipes. For a regular bidimensional network of crossed identical pipes it is possible to construct a model of dispersion of contamination.

We shall consider a constantly producing contaminant source. The source is located in one of the pipes. The direction of seepage velocity can change at any corner of a fracture. In each fracture intersection there is a complete mixing of entering waters. The contaminant concentration of the exiting solution is defined by the formula of mixing (Figure 3.1).

$$
\mathrm{C}_{3}=\mathrm{C}_{4}=\frac{\mathrm{q}_{1} \mathrm{C}_{1}+\mathrm{q}_{2} \mathrm{C}_{2}}{\mathrm{q}_{1}+\mathrm{q}_{2}} .
$$

The numerical experiment was carried out for a bidimensional network of identical fractures with identical distance between them. The discharge ratios on axes of coordinates $q_{y} / q_{x}=a=$ $0.1,0.2,0.3, \ldots .0 .9$; it is obvious that at a $=0$ or 1 , transverse hydrodynamic dispersion is not present. The results were compared to the analytical solution for anisotropic environs:

$$
\begin{aligned}
& \left.\frac{\mathrm{C}}{\mathrm{C}_{0}}=\frac{\mathrm{r}}{\sqrt{\pi \chi \varepsilon \delta \sqrt{1+(\alpha / \varepsilon)^{2}}}} \exp \left\{-\frac{(\zeta-\alpha \chi)^{2}}{\mathrm{~N}} / 4 \delta\left(\chi \varepsilon \sqrt{1+(\alpha / \varepsilon}+\frac{\alpha}{\varepsilon} \cdot \frac{\zeta-\alpha \chi}{\sqrt{1+(\alpha / \varepsilon)^{2}}}\right)\right]\right\} \\
& \mathrm{D}=\delta v ; \varepsilon=\sqrt{\mathrm{D}_{\mathrm{x}}} / \mathrm{D}_{\zeta} ;
\end{aligned}
$$

where $r$ is the radius of a source, $\varepsilon$ the coefficient of anisotropy, $\chi$ the coordinate on a direction of seepage velocity, $\zeta$ the coordinate perpendicular to seepage velocity, $\delta$ the dispersivity.

The distributions of transverse cross dispersivity and coefficient of anisotropy are shown on Figure 3.1. It appears that the radius of a source is equal to the square root of the distance between joints. 


\subsection{Model of Contaminant Migration in a Limestone Aquifer}

From the above, it follows that the zone of an increased permeability does not have a determined thickness, and its hydrogeological parameters make sense only in a complex with thickness, for example $\mathrm{T}=\mathrm{km} ; \mathrm{q}=\mathrm{nm}, \mathrm{Dm} ; \mathrm{nm}$. The basic scheme of contaminant propagation is shown on Figure 3.2. Environs of contaminant migration are supposed heterogeneous with threefold capacity - thin zone, fractures of dividing low permeable layers and blocks of rocks.

The model of contaminant transport in a thin permeable zone in a monodimensional case is expressed

$$
\begin{aligned}
& \frac{\partial}{\partial \mathrm{x}}\left(\mathrm{Dm} \frac{\partial \mathrm{C}}{\partial \mathrm{x}}\right)-\frac{\partial(\mathrm{qC})}{\partial \mathrm{x}}-2 \mathrm{~J} *-\mathrm{w}_{\mathrm{u}}^{\prime} \mathrm{C}+\mathrm{w}_{\mathrm{d}}^{\prime} \mathrm{C}_{0}-\mathrm{nm} \frac{\partial \mathrm{C}}{\partial \mathrm{t}}=0 ; \\
& \mathrm{J}^{*}=-\left.\mathrm{D} * \frac{\partial \mathrm{C} *}{\partial \mathrm{y} *}\right|_{\mathrm{y}^{*}=0}
\end{aligned}
$$

Transport in a low permeability layer with thickness of a few meters, is described by the usual convection-diffusion equations

$$
\begin{aligned}
& \mathrm{D}^{\prime} \frac{\partial^{2} \mathrm{C}^{\prime}}{\partial \mathrm{z}^{2}}-\mathrm{w}^{\prime} \frac{\partial \mathrm{C}^{\prime}}{\partial \mathrm{z}}-2 \mathrm{~J} *-\mathrm{n}^{\prime} \frac{\partial \mathrm{C}^{\prime}}{\partial \mathrm{t}}=0 ; \\
& \mathrm{J}^{*}=-\left.\mathrm{D}^{*} \frac{\partial \mathrm{C} *}{\partial \mathrm{y} *}\right|_{\mathrm{y}^{*}=0} .
\end{aligned}
$$

Transport within the rock is described by the diffusion equation

$$
\mathrm{D} * \frac{\partial^{2} \mathrm{C}^{*}}{\partial \mathrm{y} * 2}-\mathrm{n} * \frac{\partial \mathrm{C}^{*}}{\partial \mathrm{t}}=0
$$

All designations without the top index belong in the thin zone, with a stroke to fractures of a low permeability layer, with an asterisk to blocks of rocks.

Using Laplace transformations it is possible to determine a series of analytical solutions for contaminant migration. The solutions are then applied to determination of mass transfer parameters. Use of the model for real cases is shown below. 


\subsection{Modeling Mass Transfer in Limestone Aquifer}

The bidimensional cross section model was created for five permeable zones. The source of pollution is located on the surface of the ground. The pollution enters the top thin permeable zone by infiltration. From this zone it moves to the pumping well and leaks through a low permeable layer in the adjacent zone. Absence of microdispersion in a low permeable layer is assumed. However, mass exchange exists between fractures and blocks. Furthermore, the process repeats. We were interested in concentration dependence with time in pumping wells.

The mass transfer model resembles that obtained in section 3.2. The solution of the equations for permeable zones were obtained numerically, and for low permeable layers, analytically. The solution of the equations for heterogeneous-blocks environs was:

$$
\begin{aligned}
& \mathrm{w}^{\prime} \frac{\partial \mathrm{C}^{\prime}}{\partial \mathrm{z}}+\mathrm{n} * \frac{\partial \mathrm{C}^{*}}{\partial \mathrm{t}}+\mathrm{n}^{\prime} \frac{\partial \mathrm{C}^{\prime}}{\partial \mathrm{t}}=0 \\
& \mathrm{n} * \frac{\partial \mathrm{C}^{*}}{\partial \mathrm{t}}=\alpha^{*}\left(\mathrm{C}^{\prime}-\mathrm{C}^{*}\right)
\end{aligned}
$$

The solution of a fundamental problem looks like the Thomas solution

$$
\mathrm{C}^{\prime}=\mathrm{F}_{\mathrm{T}}(\eta, \tau) \quad ; \eta=\frac{\alpha^{*}(1-\kappa)}{\mathrm{w}^{\prime}} ; \tau=\frac{\alpha^{*}}{\mathrm{n}^{\prime}} \cdot\left(\mathrm{t}-\frac{\mathrm{n}^{\prime} \mathrm{z}}{\mathrm{w}^{\prime}}\right) ; \kappa=\frac{\mathrm{n}^{\prime}}{\mathrm{n}^{\prime}+\mathrm{n}^{*}} ;
$$

Where $a^{*}$ is the mass exchange coefficient between fractures and blocks, $\kappa$ is the fraction of fractured porosity in the overall porosity of a layer.

The concentration of a contaminant in water entering a layer changes with time. For use of the analytical solution, a superposition of the solutions in time is applied.

$$
\mathrm{C}^{\prime}=\sum_{\mathrm{k}=0}^{\mathrm{K}}\left(\mathrm{C}_{\mathrm{k}}^{\prime}-\mathrm{C}_{\mathrm{k}-1}^{\prime}\right) \mathrm{F}(\eta, \tau) ; \mathrm{C}_{-1}^{\prime}=0
$$

For fast computation an approximation was used:

$$
C^{\prime}=F(\eta, \tau) \approx 0.5 \operatorname{erfc}(\sqrt{\eta}-\sqrt{\tau})
$$

correct in our case for $t>5$ day. The results are shown in Figure 3.3. 
The most interesting is the step type of curve of contaminant concentration in the pumping well. Steps of concentration stabilization require $2-4$ years. Hence, it is possible to obtain a deceptive picture of pollution stabilization by only monitoring of contaminant.

Comparison of the determined dependence of concentration over time with the analytical solutions for similar layers, taking into account microdispersion, has shown:

- The concentration in the model grows faster than with the analytical solutions,

- The distinctions are increased with growth of porosity of limestones blocks.

The degree of influence of the hydrogeological characteristics on mass transfer decreases in the following order:

- Distribution of thin permeable zones' transmissivities;

- Common transmissivity of an aquifer;

- Porosity of rock blocks;

- Coefficient of mass exchange between blocks and fractures in low permeable layers;

- Leakage coefficient of low permeable layers.

It is interesting that the accuracy of determination of mass transfer parameters of thin permeable zones, namely specific capacity and dispersivity, does not practically influence the accuracy of the forecast. However only these parameters are determined in field experiments.

\section{Acknowledgment}

The paper was prepared under the auspices of Russian-American Center for Contaminant Transport Studies at the Lawrence Berkeley National Laboratory. We appreciate the funding support from the Office of Energy Research, Engineering and Geosciences Division of the U.S. Department of Energy through Contract Number DE-AC13-76SF00098.

We thank Dr. Anil Mishra and Harold Wollenberg for their review, comments, and editorial improvements. We should like to express sincere gratitude to Dr. Chin-Fu Tsang for his support and encouragement. 


\section{References}

Chave K. and Schmals R. Carbonate - seawater interactions. Geochim. Cosmochim. Acta, 1966, v. 3, p. 1037-1049.

Lekhov A.V. Modeling of karst process. 1. Construction of theoretical model of karst process. Engineering geology, 1981, No. 1, p. 89-96.

Lekhov A.V. Modeling of karst process. 2. Theoretical research of mass exchange models for fractured in karstifiable rocks. Engineering geology, 1981, No. 4, p. 70-79.

Lekhov A.V. Analytical research of aperture change for individual fracture of karstifiable rocks. Engineering geology, 1984, No. 6, p. 63-73.

Lekhov A.V. Mathematical modeling karst process in group of fractures. Engineering geology, 1985, No. 5, p. 61-67.

Lekhov A.V. Physical-chemical conditions of karst distribution in carbonate rocks massif. Engineering geology, 1986, No. 5, p. 61-67.

Lekhov A.V., Lebedev A.L., Fockina L.M. Kinetics and dynamics of limestone dissolution. Geochemistry, 1984, No. 11, p. 1757-1766.

Lekhov M.V., Lekhov A.V., Malosemov A.V. A substantiation of the circuit transmissivity scheme low permeable limestone aquifer. Engineering geology, 1986, No. 6, p. 44-51.

Lekhov A.V. and Petrov A.L. Determination of transport parameters at migration experiments in fractured and karstic rocks breeds. Waters Resources, 1988, No. 4, p. 33-40.

Lekhov A.V. Physical-chemical models of hydrodynamics of carbonate karstifiable rocks massifs. D. Sc. thesis, Moscow: MSU, 1988, 250 p.

Lebedev, A.L. and Lekhov A.V. Kinetics of dissolution of natural gypsum in water at 5-25 $5^{\circ}$. Geochemistry, 1989, No. 6, p. 865-874.

Mulli A., Morse J.W., Kaminsky M.S. Auger spectroscopy analysis of magnesian calcite overgrowths precipitated from sea-water and solutions of similar composition. Amer. J. Sci., 1985 , v. 285, N. 4 , p.289-305. 
Petrov A.L. and Lekhov A.V. Some questions of a technique migration experiments at carbonate aquifer. Waters Resources, 1986, No. 2, p. 11-19.

Plummer L.N. and Mackenzie F.T. Prediction mineral solubility from rate data: Application to the dissolution of calcites. Amer. J. Sci., 1974, v. 274, N. 1, p. 61-83.

Rybnikova L.S. and Lekhov A.V. Modeling of mass transfer in limestone aquifer. Waters Resources, 1986, No. 1, p. 55-64. 


\section{Figure Captions}

Fig. 1.1. Main calcite characteristics.

Fig. 1.2. Kinetics of calcite dissolution (wall of fracture).

Fig. 1.3. Dynamics of fracture wall dissolution.

Fig. 1.4. Increase of single fracture width.

Fig. 2.1. (a) Increase of apertures for a group of fractures.

(b) Step of fracture aperture growth (for a group).

(c) Behavior of a group of fractures (top) and single fractures (bottom) with wall dissolution.

Fig. 2.2. (a) Structure of a thin permeable zone.

(b)Distribution of thin karstic zones in limestone massif with horizontal layers.

(c) Distribution of zones in monoclinal massif.

Fig. 2.3 Field measurements.

Fig. 3.1. Hydrodispersion in a thin permeable zone.

Fig. 3.2. Model of contaminant transport (three-capacity environs).

Fig. 3.3. Simulation of mass transfer in limestone aquifer. 

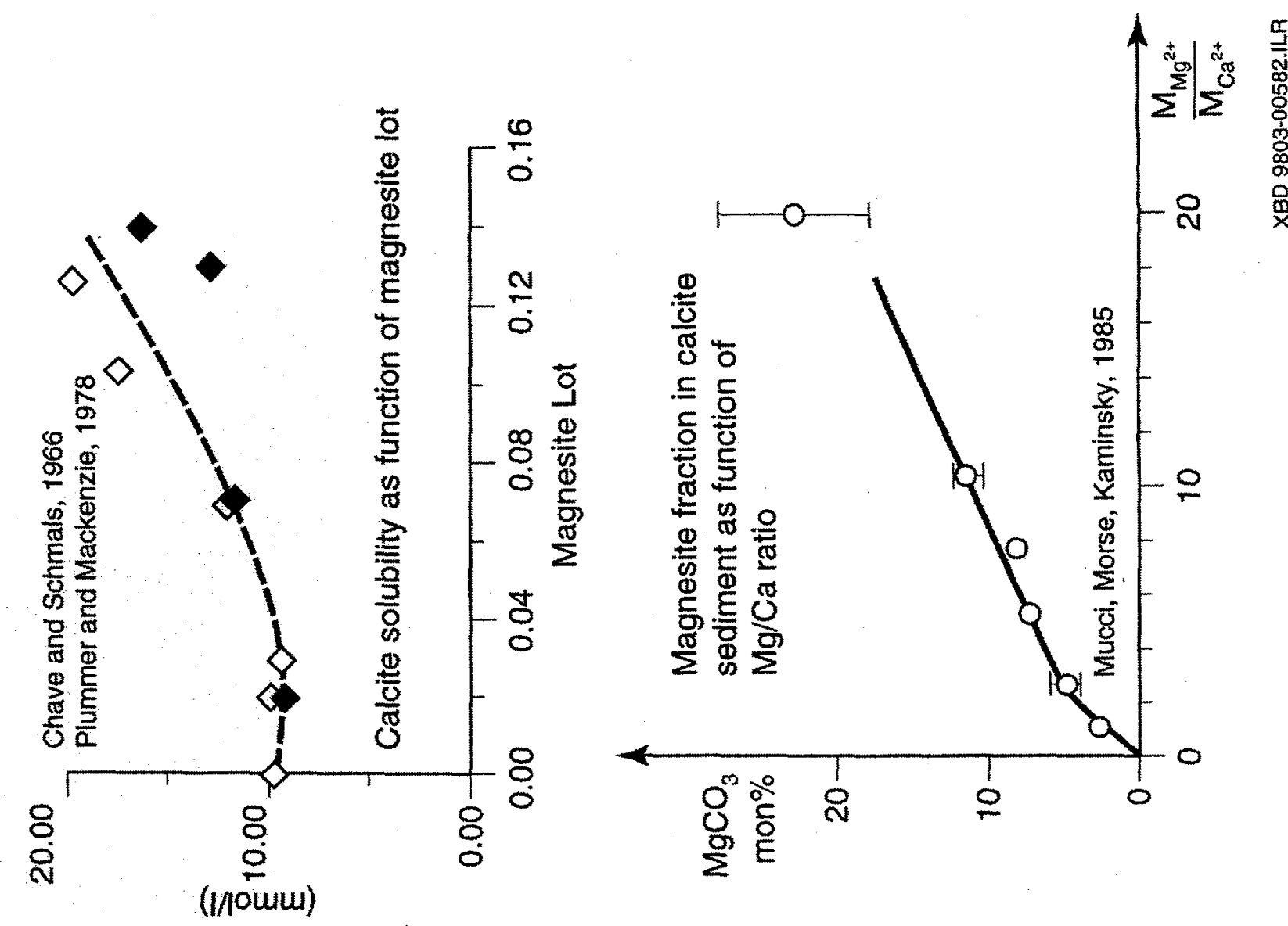

0
$\frac{0}{0}$
$\frac{0}{4}$
$\frac{1}{0}$
$\frac{\pi}{\sigma}$
$\frac{\sigma}{0}$

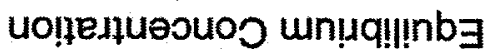
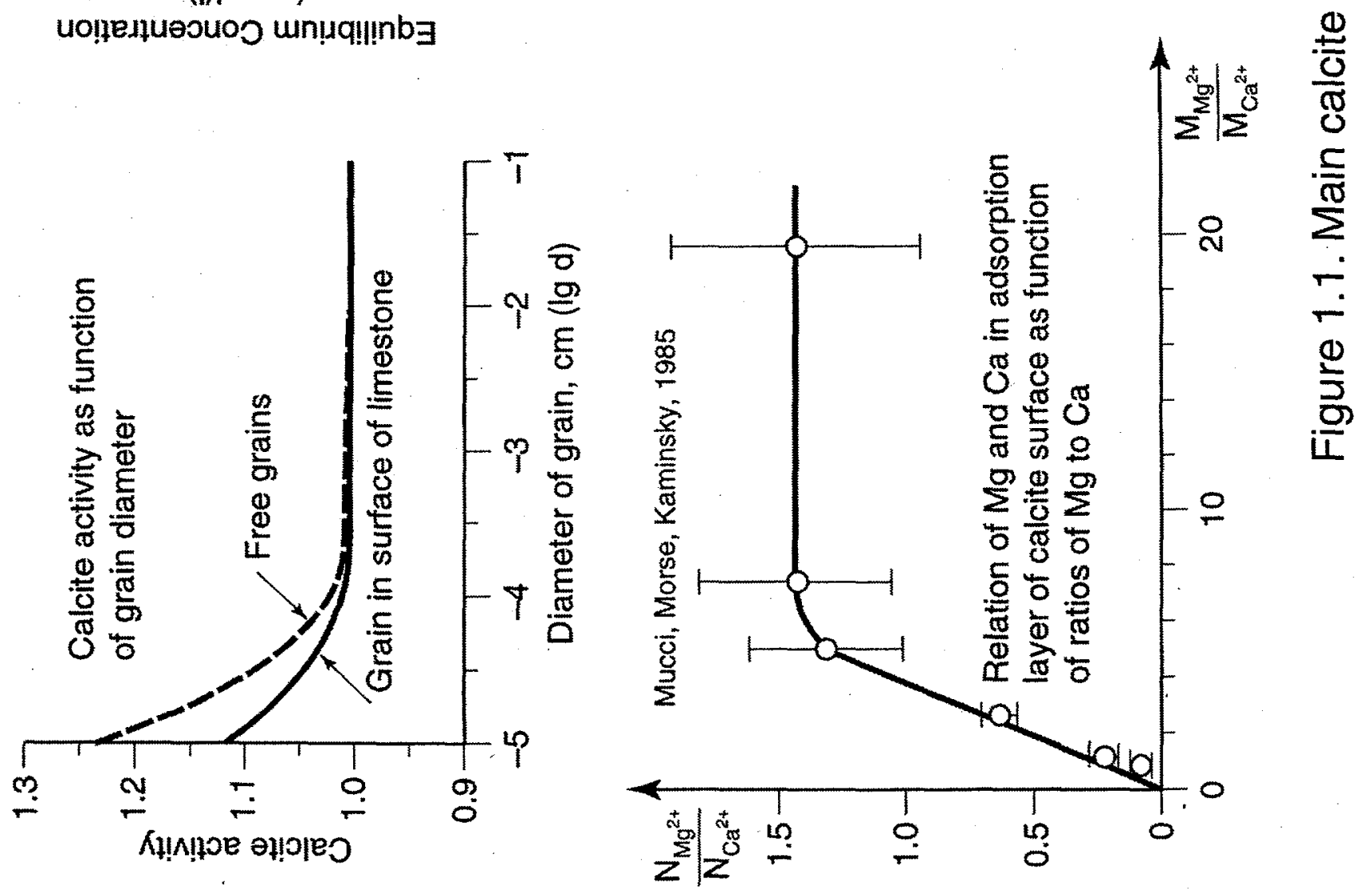


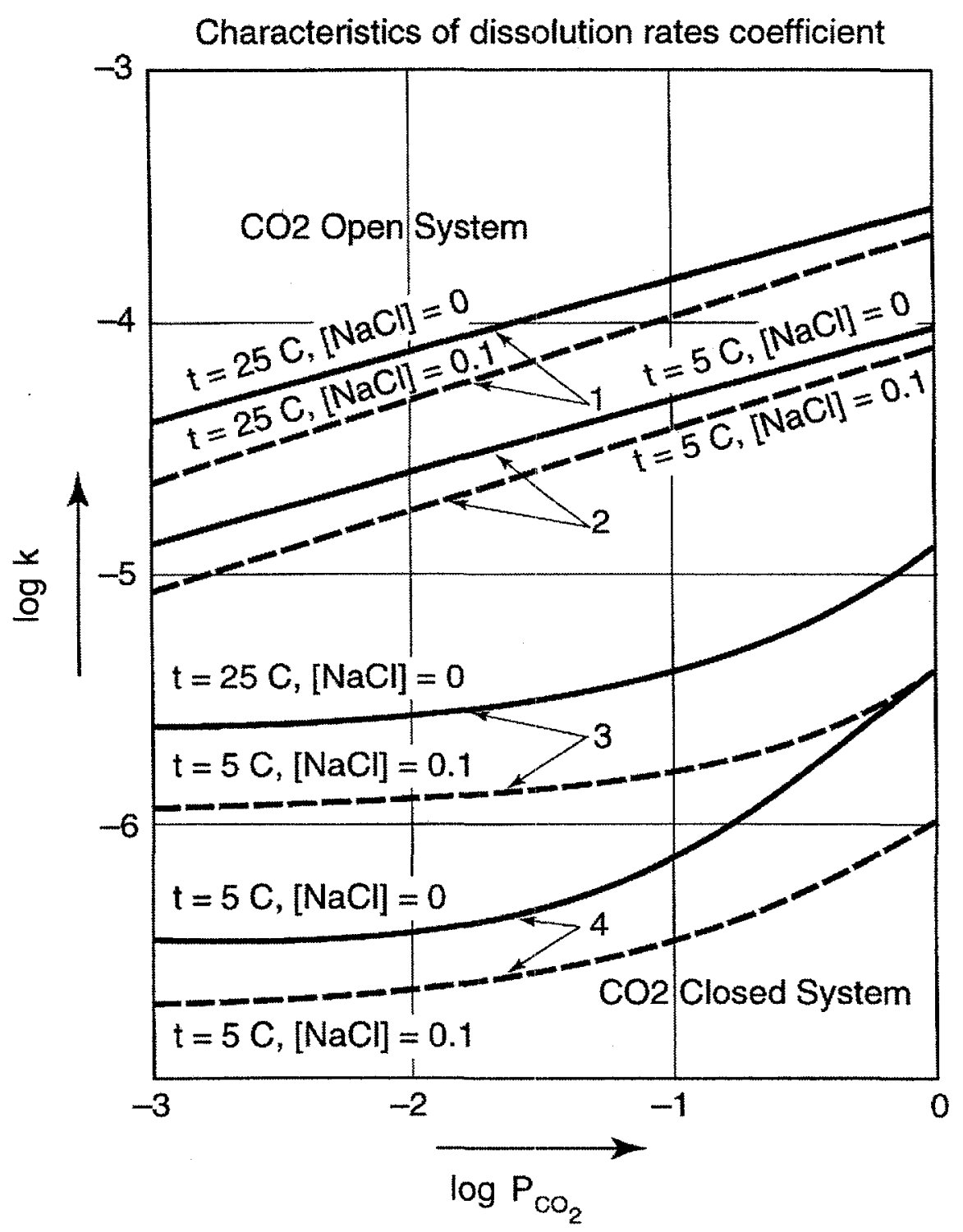

Estimation of dissolution velocity coefficient $0.00003 \mathrm{~cm} / \mathrm{s}$ $(t=5 \mathrm{C}$ and $\mathrm{CO} 2$ closed system with initial $\mathrm{P}(\mathrm{CO} 2)=0.01$ bar $)$

Fig. 1.2. Kinetics of calcite dissolution (wall of fracture) 


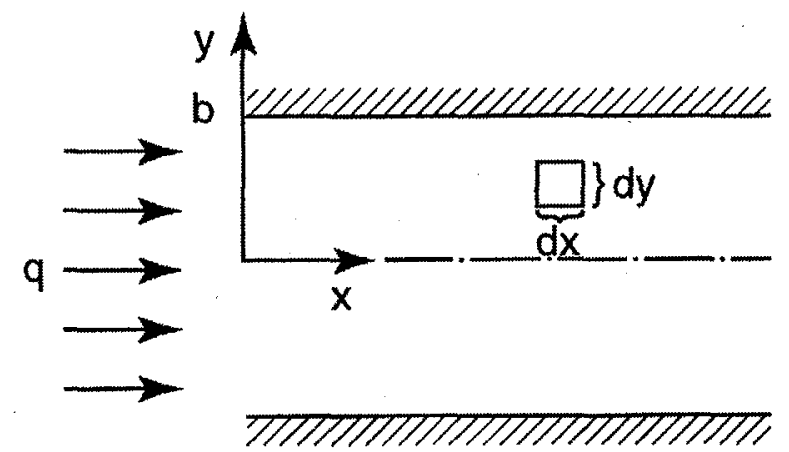

N

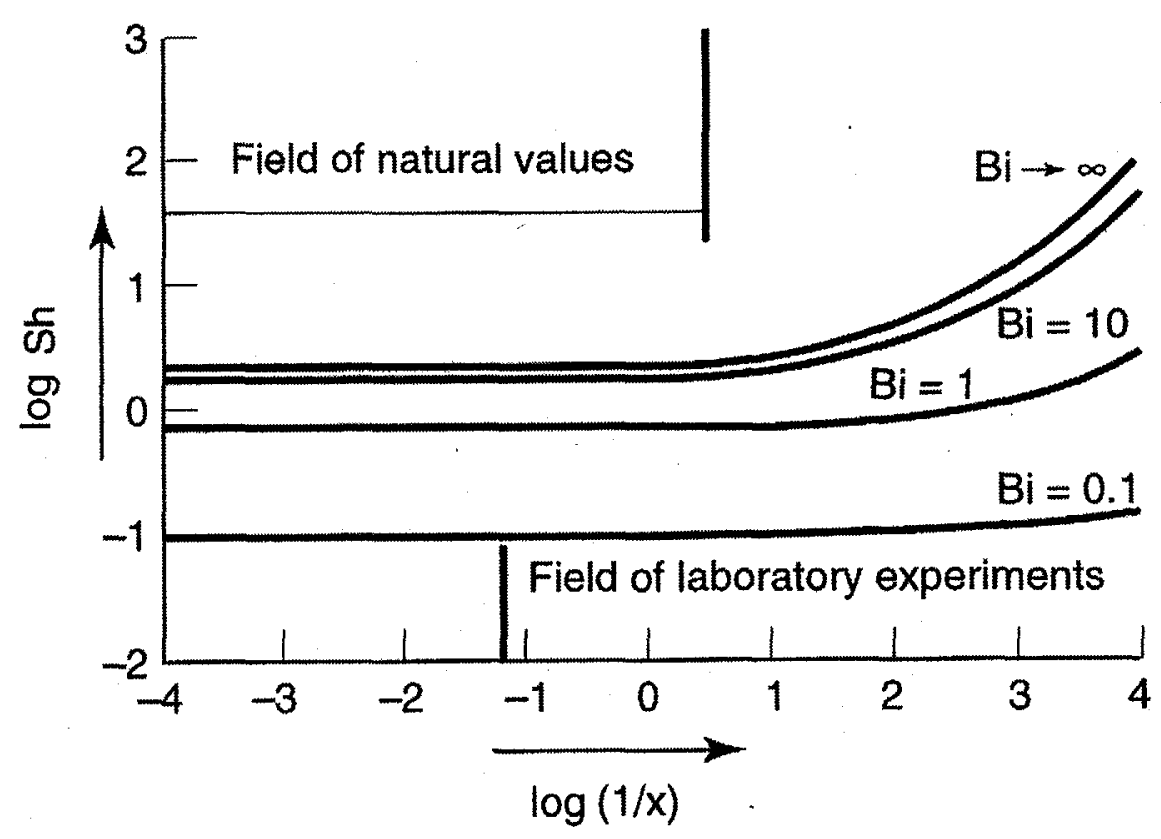

$S h=\alpha b / D ; B i=\kappa b / D ;$ $q=u / b ; \bar{x}=2 D x /\left(3 u b^{2}\right)$

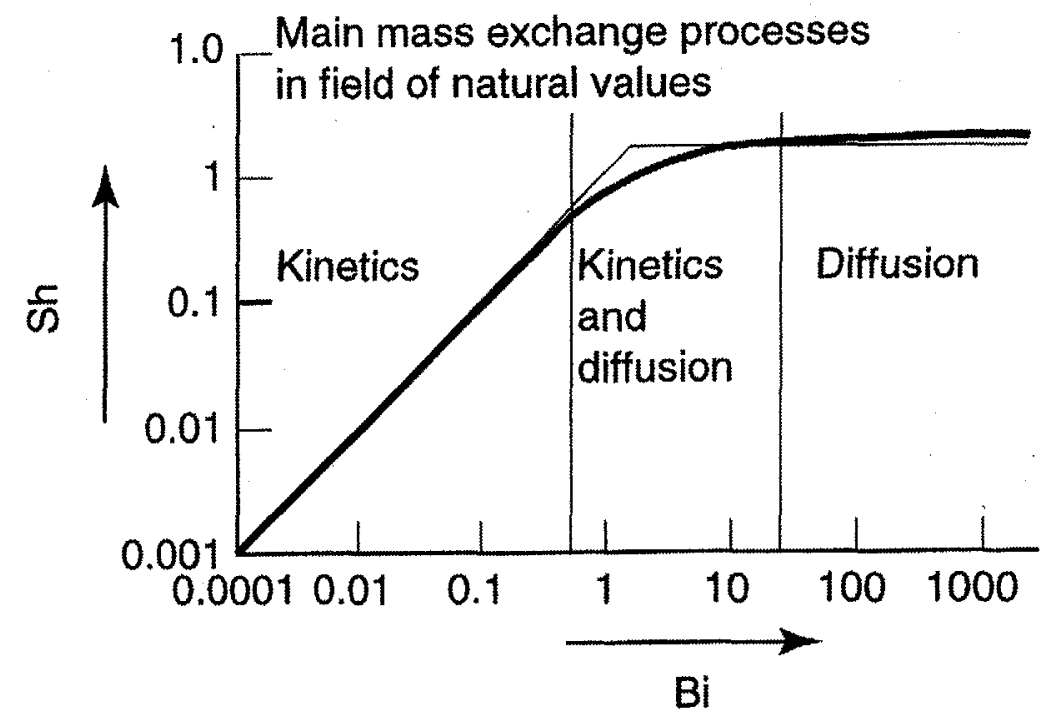

Fig. 1.3. Dynamics of fracture wall dissolution 


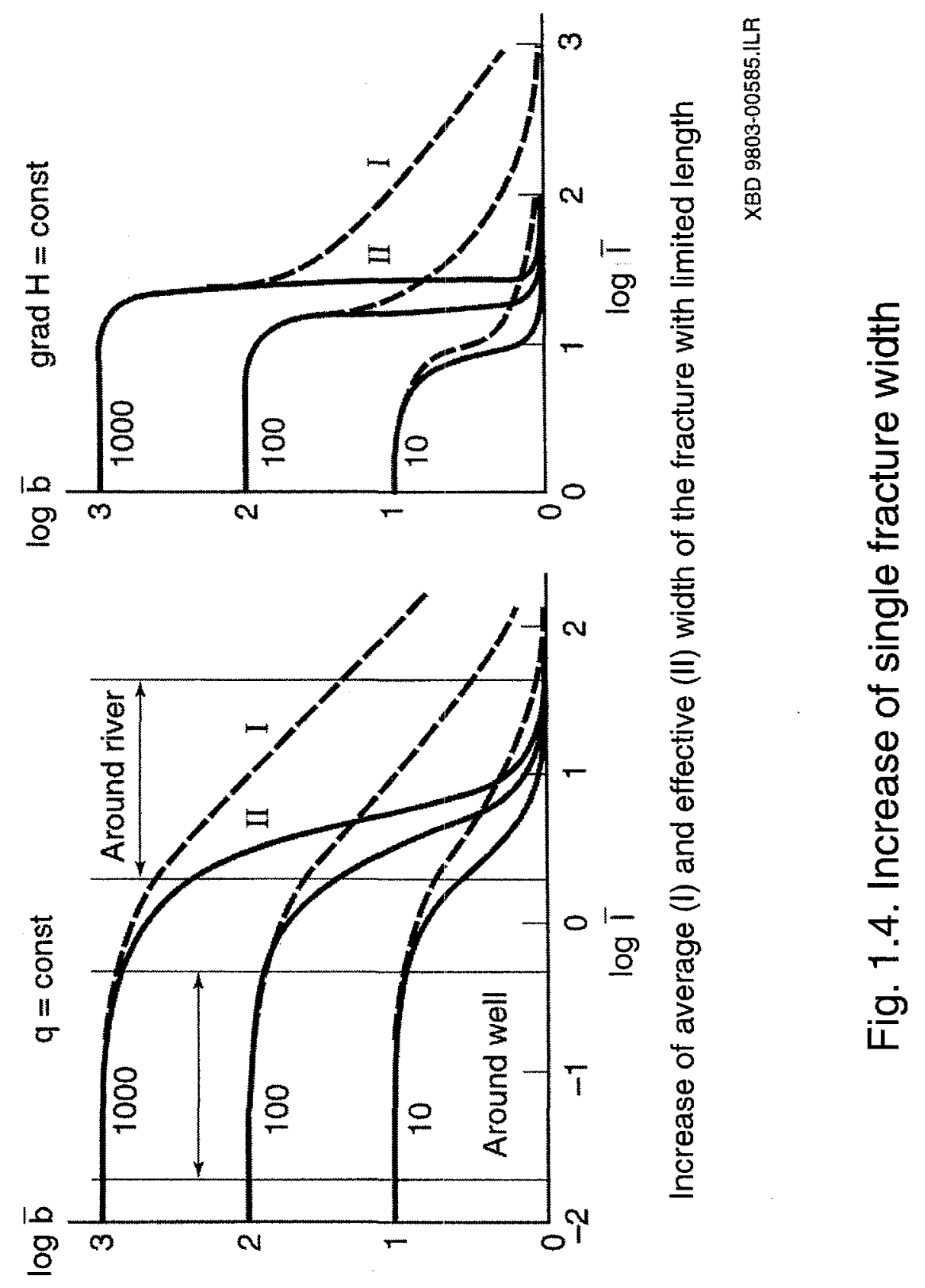



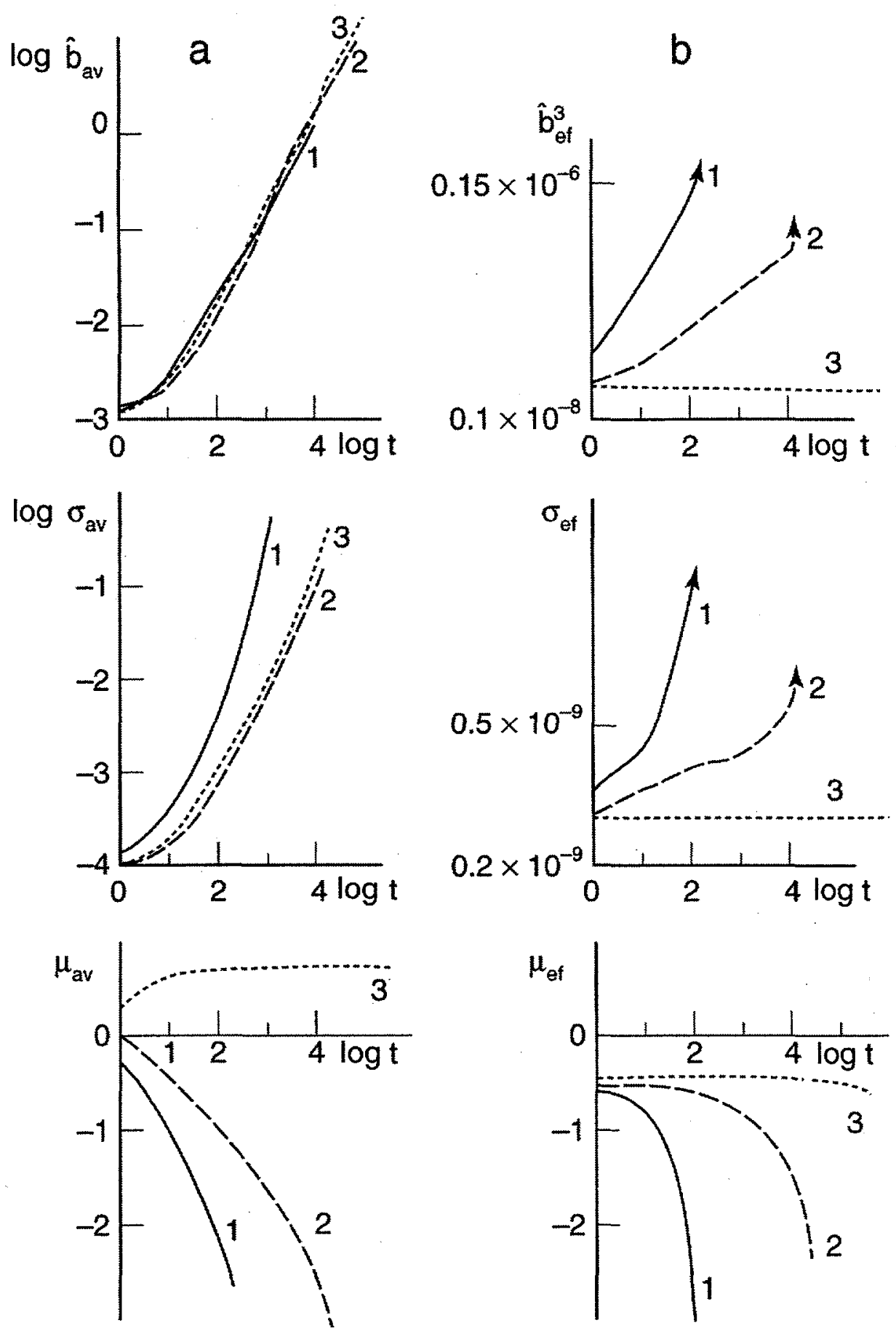

$\mathrm{C}_{\mathrm{m}}-\mathrm{C}=10^{-4} \mathrm{~mol} / \mathrm{ml} ; \mathrm{k}=3 \cdot 10^{-5} \mathrm{~cm} / \mathrm{s} ; \mathrm{I}=10 \mathrm{~cm}$;

$b_{0}=10^{-3} \mathrm{~cm} ; \sigma_{0}=10^{-4} \mathrm{~cm} ; \mathrm{I}=100$.

1) $Q=10^{-4} \mathrm{~cm}^{2} / \mathrm{s}$; 2) $Q=5 \cdot 10^{-4} \mathrm{~cm}^{2} / \mathrm{s}$; 3) $Q=10^{-3} \mathrm{~cm}^{2} / \mathrm{s}$;

Fig. 2.1.a. Increase of apertures for a group of fractures 


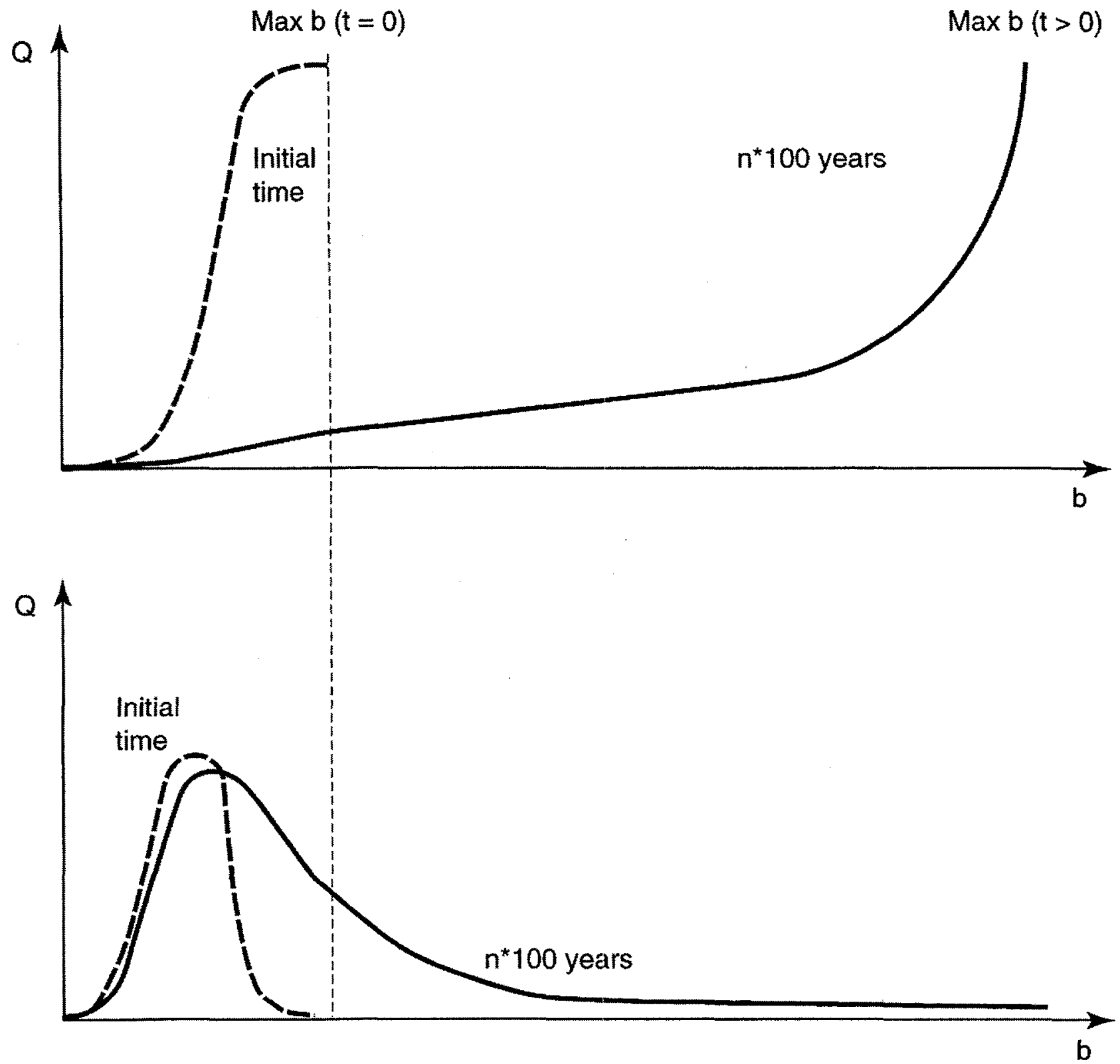

Cumulative curves of discharges as function of fracture apertures for group of fractures $(Q=$ const $)$ and aperture distribution

XBD 9803-00587.ILR

Fig. 2.1.b. Step of fracture aperture growth (for a group) 

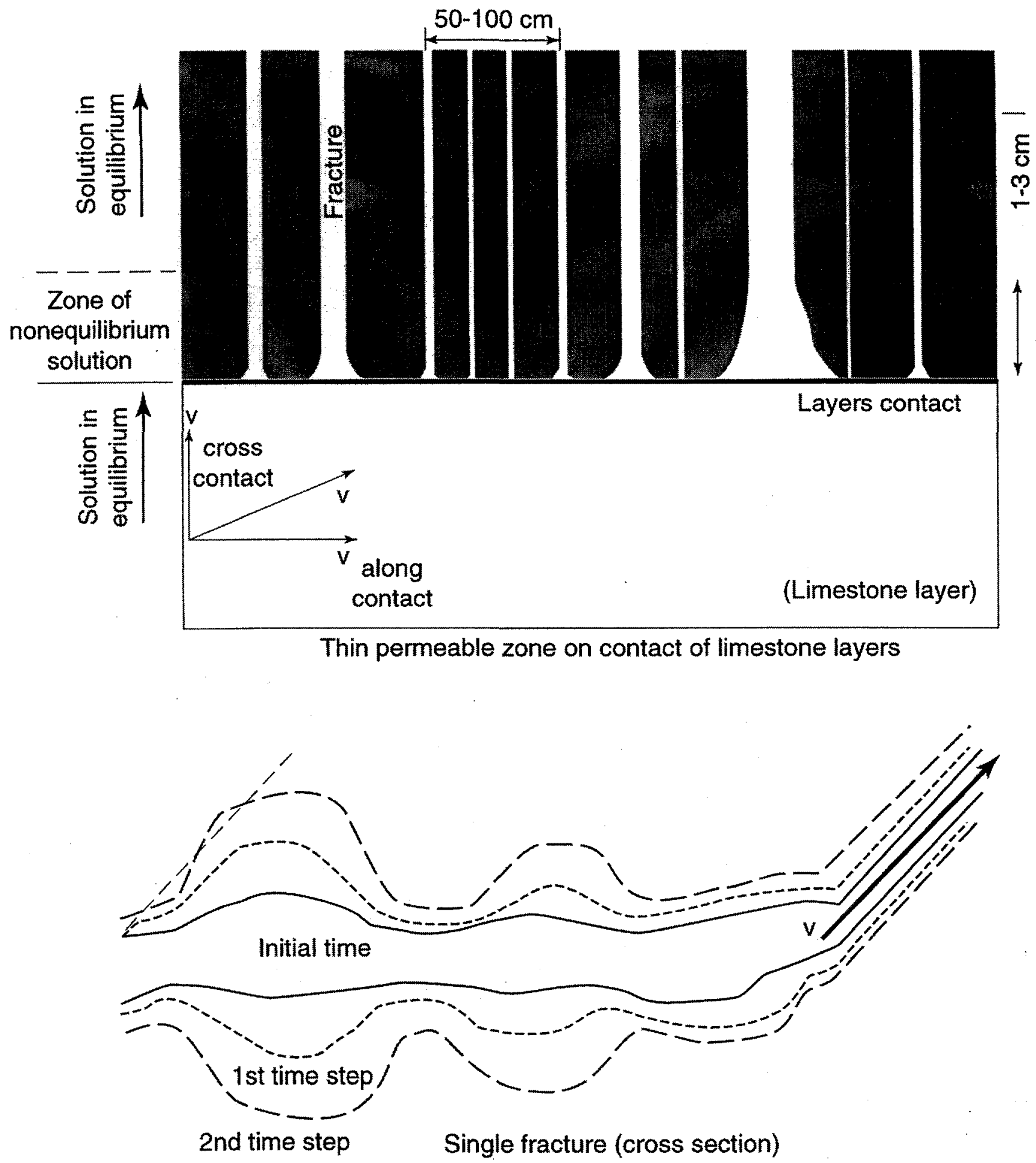

XBD 9803-00588.ILA

Fig. 2.1.c. Behavior of a group of fractures (top) and single fractures (bottom) at walls dissolution 

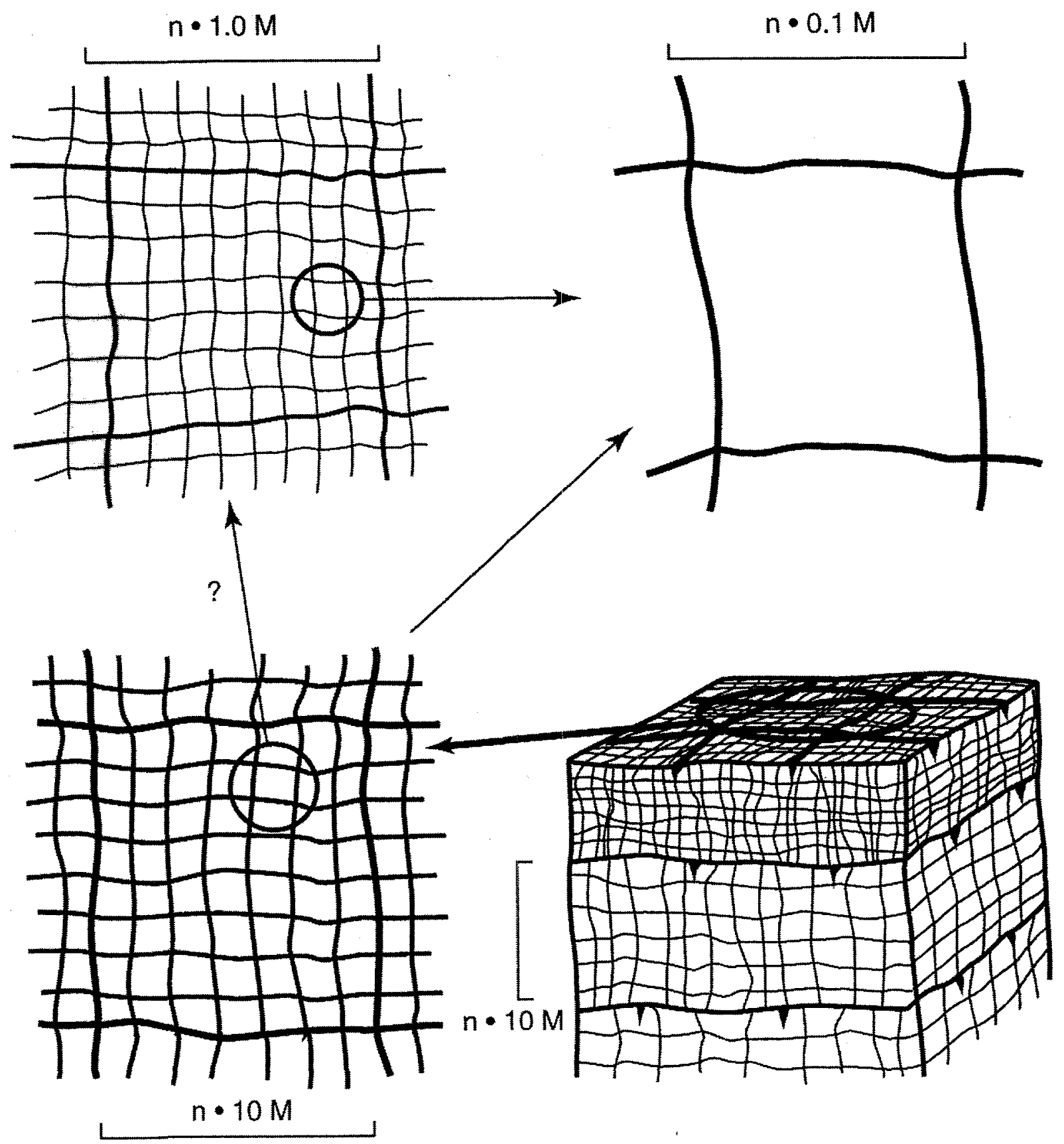

XBD 9803-00589.1LR

Fig. 2.2.a. Structure of a thin permeable zone 


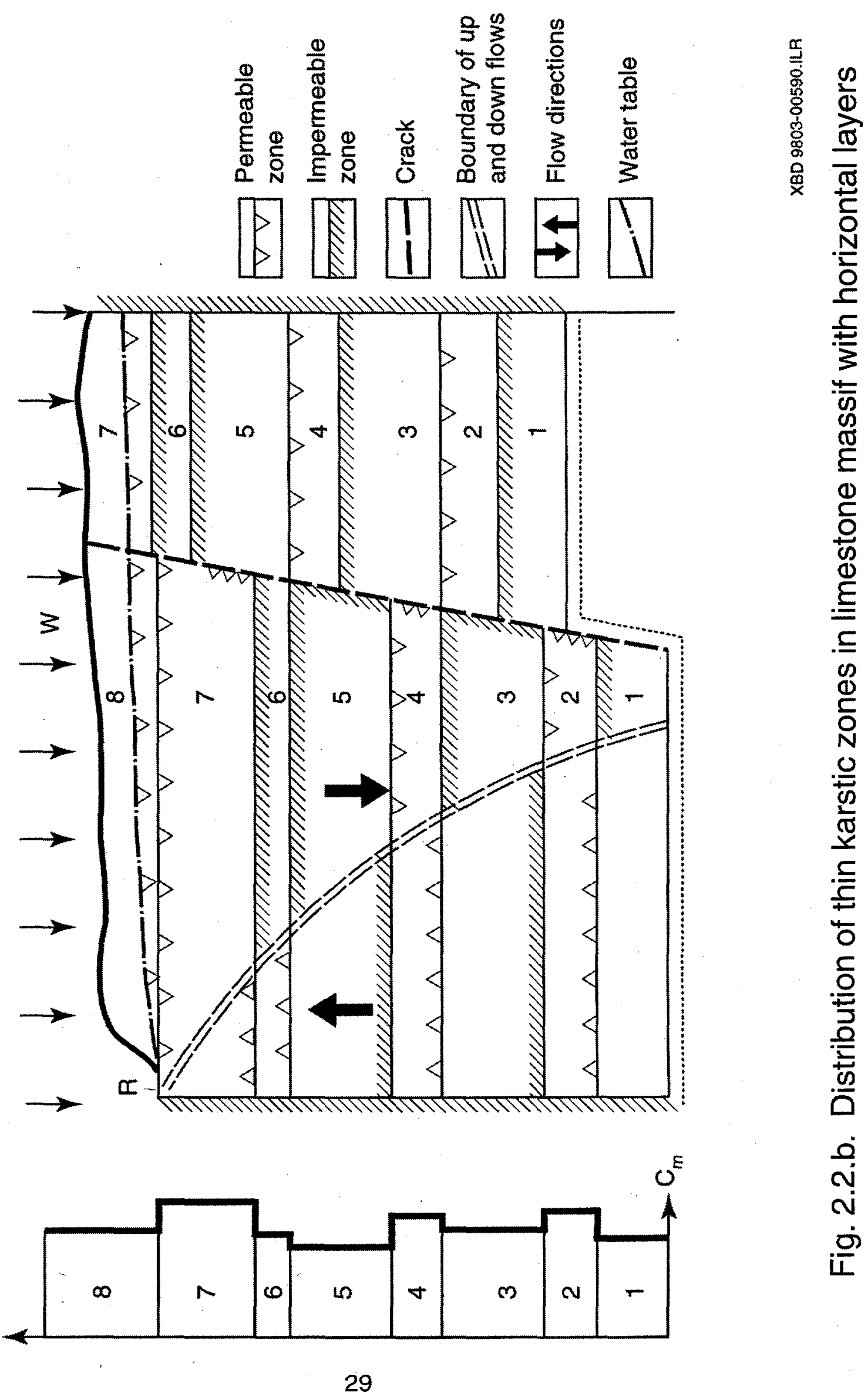




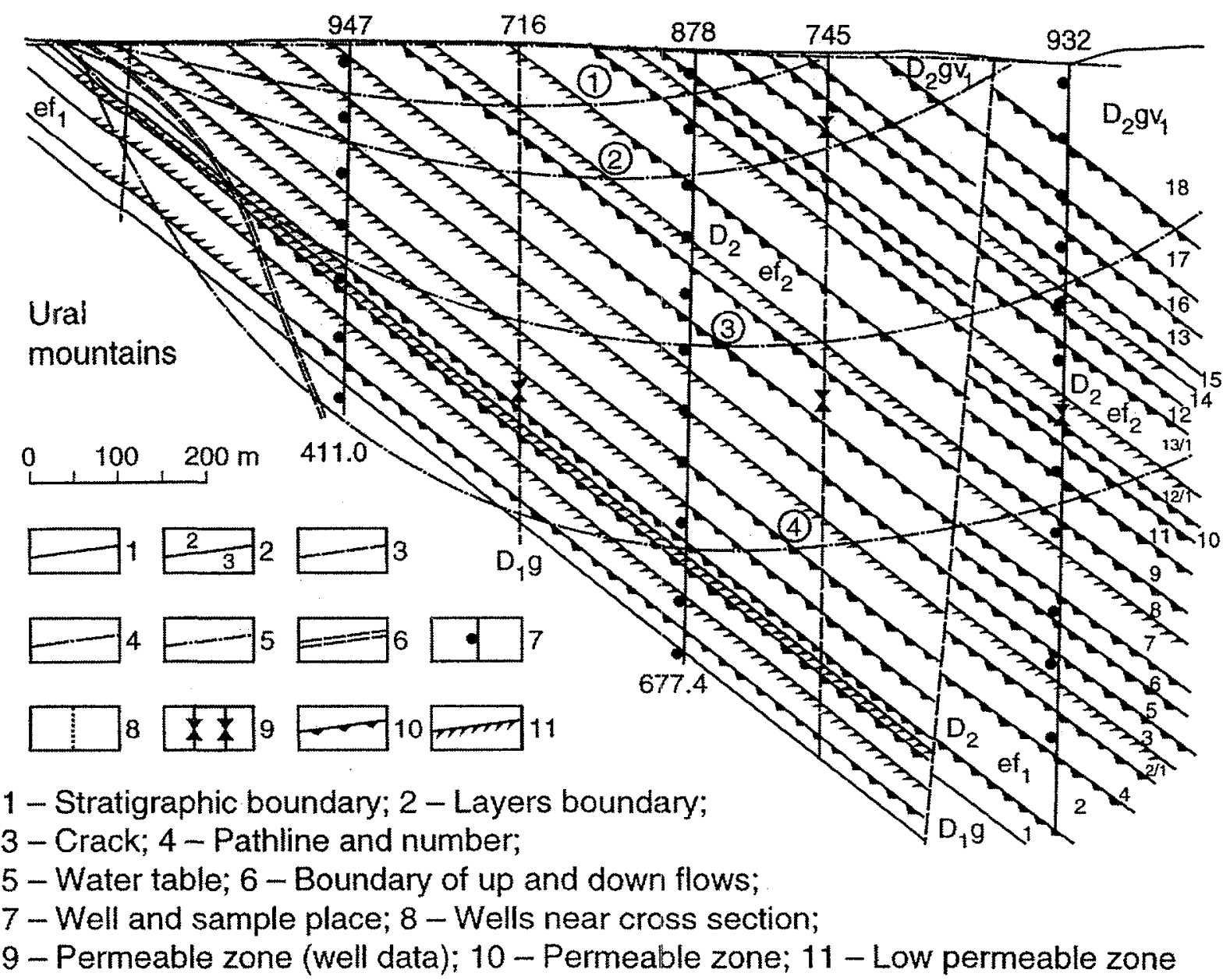

Calcite dissolution (+) and precipitation (-) along pathlines

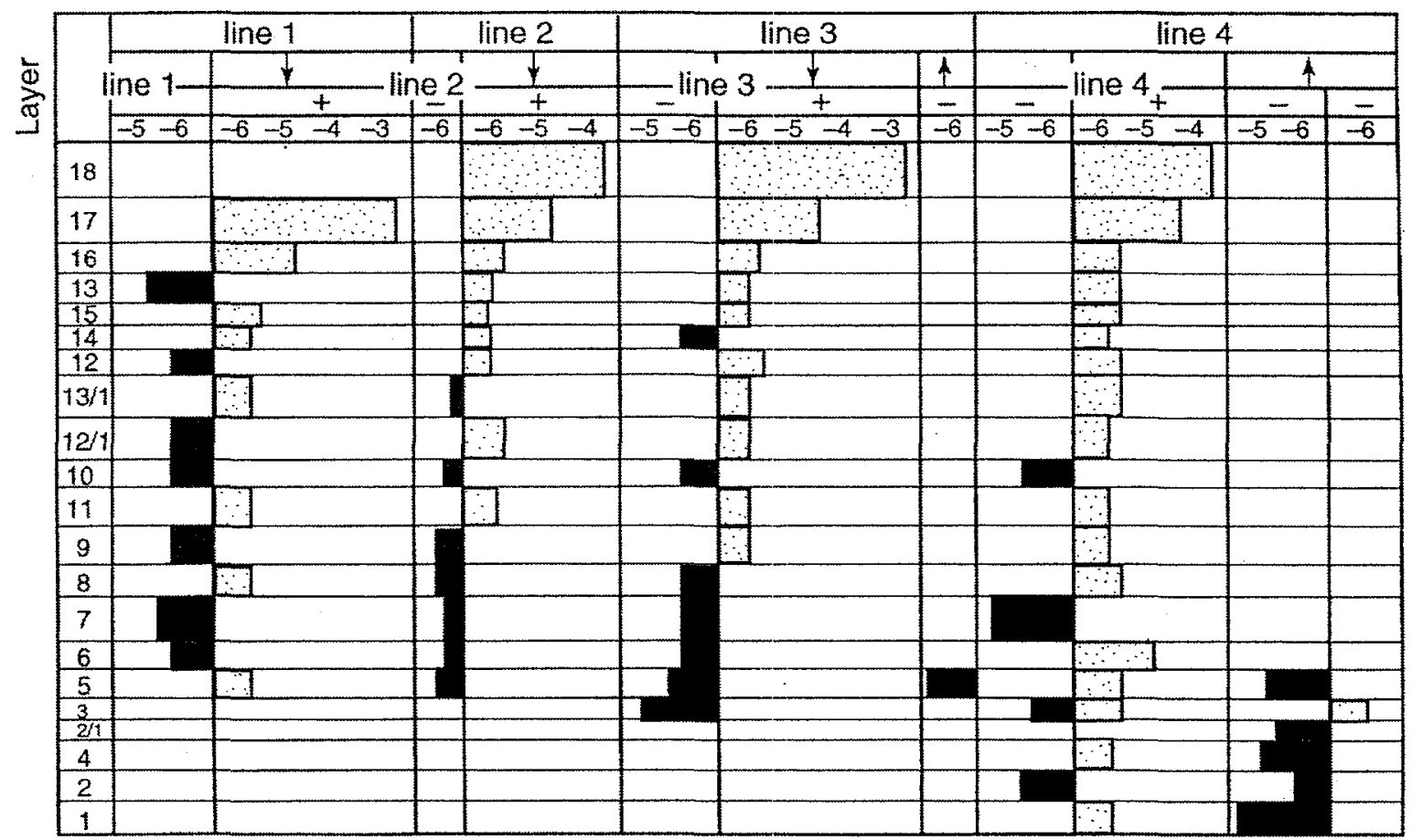

Fig. 2.2.c. Distribution of zones in monoclinal massif 


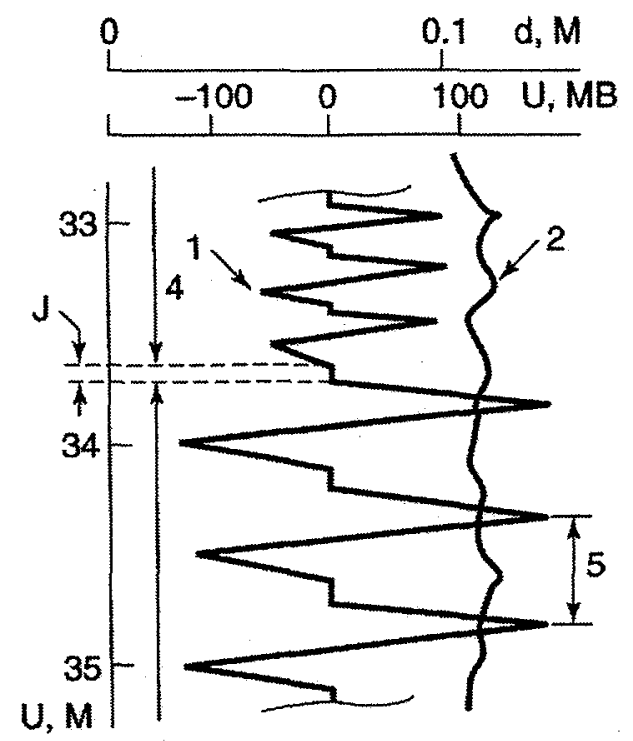

The search for thin zones of permeability
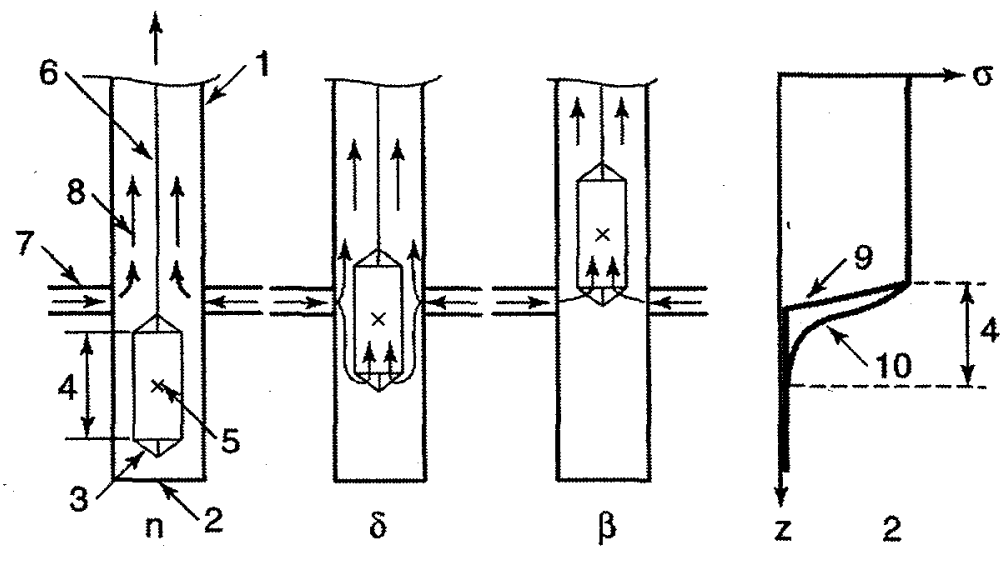

Results of searching and correlating zones in a carbonate aquifer

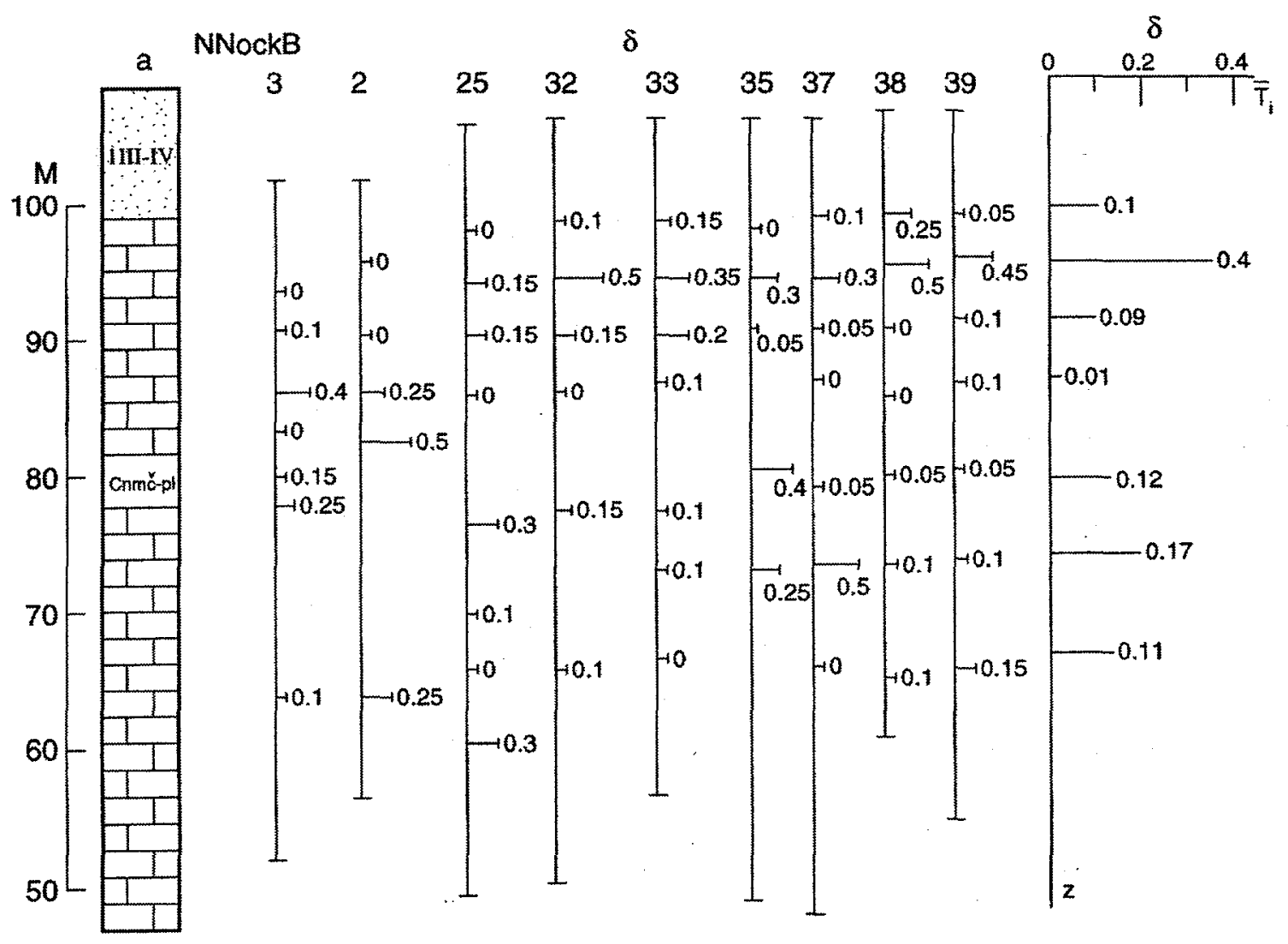

XBD 9803-00592.ILR

Fig. 2.3. Field measurements 

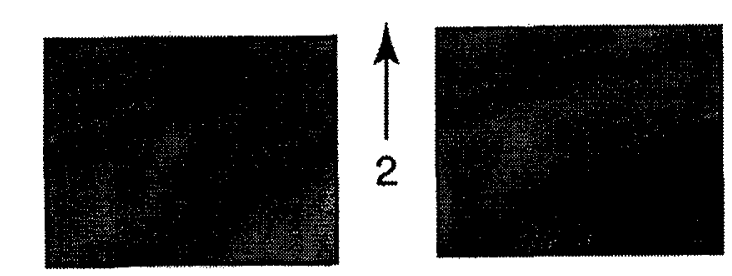

$\longrightarrow 1$
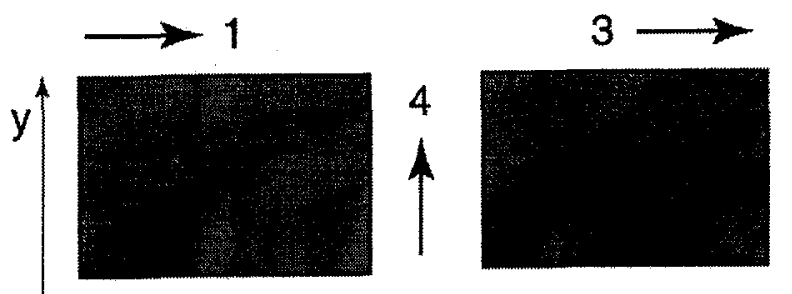

$x$

Fracture node

with complete mixture

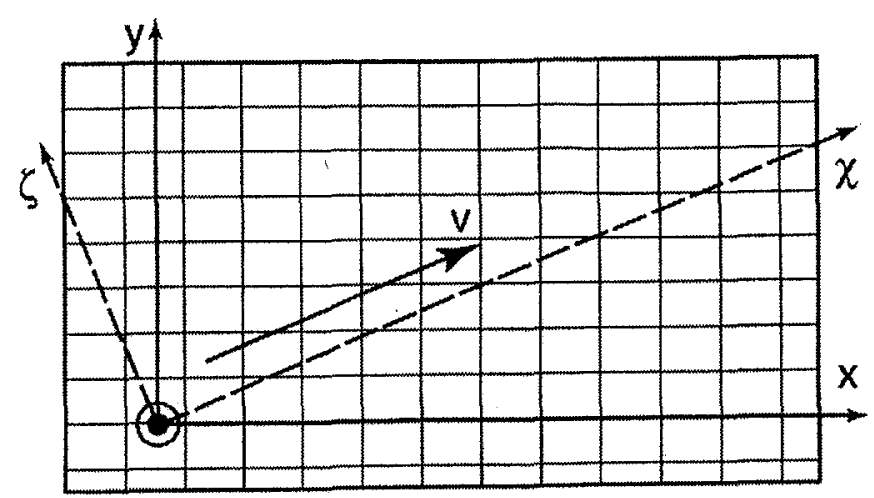

Coordinates for 2 systems of fractures channels, tubes and for flow with hydrodispersion

Solution for transversal hydrodispersion in anisotropic environs (point source)

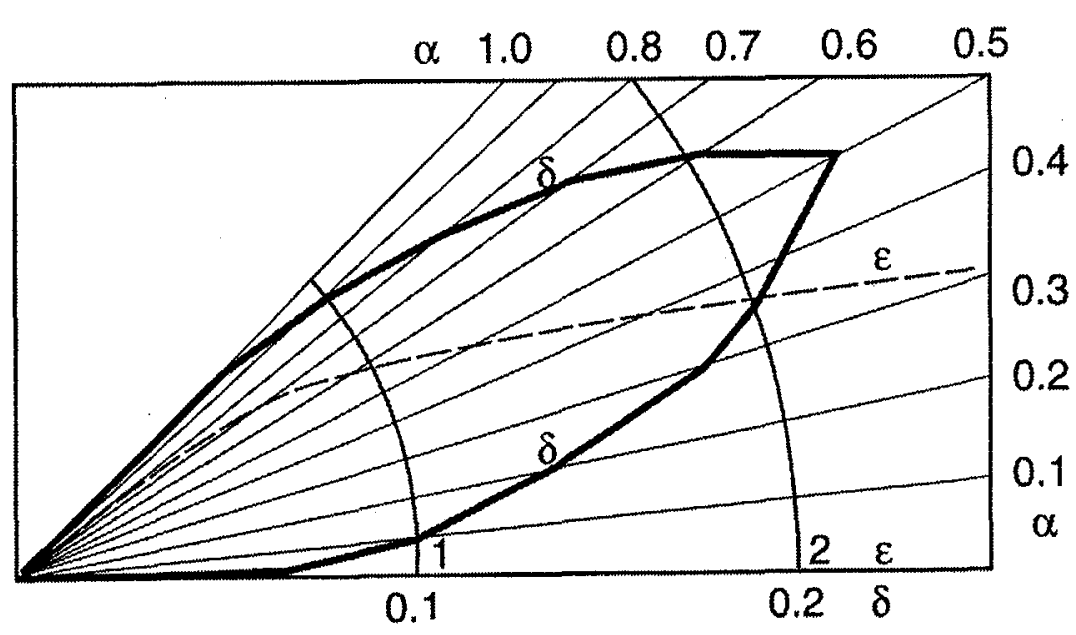

Dispersivity and anisotropic coefficient as function of flow direction

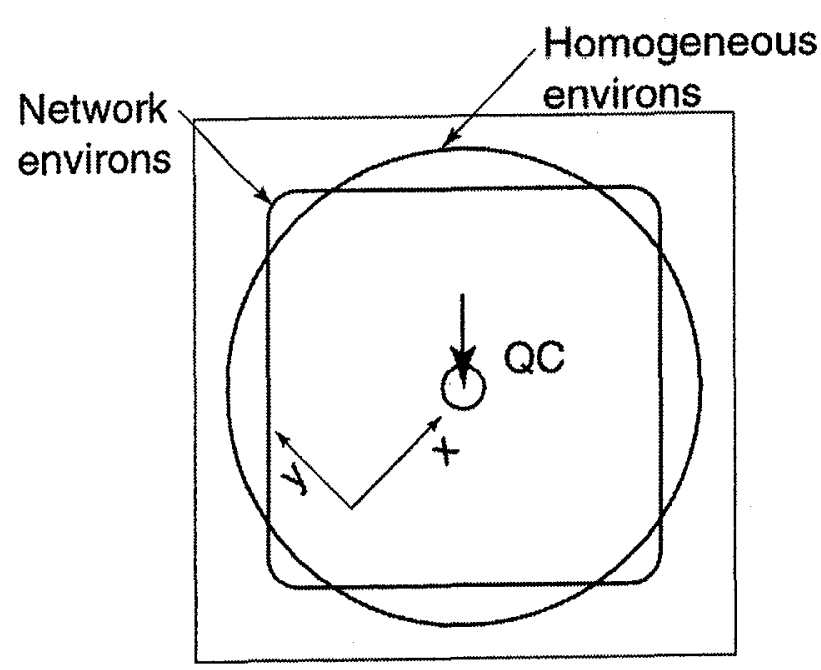

Contours of migrant area in well injection

Fig. 3.1. Hydrodispersion in a thin permeable zone 


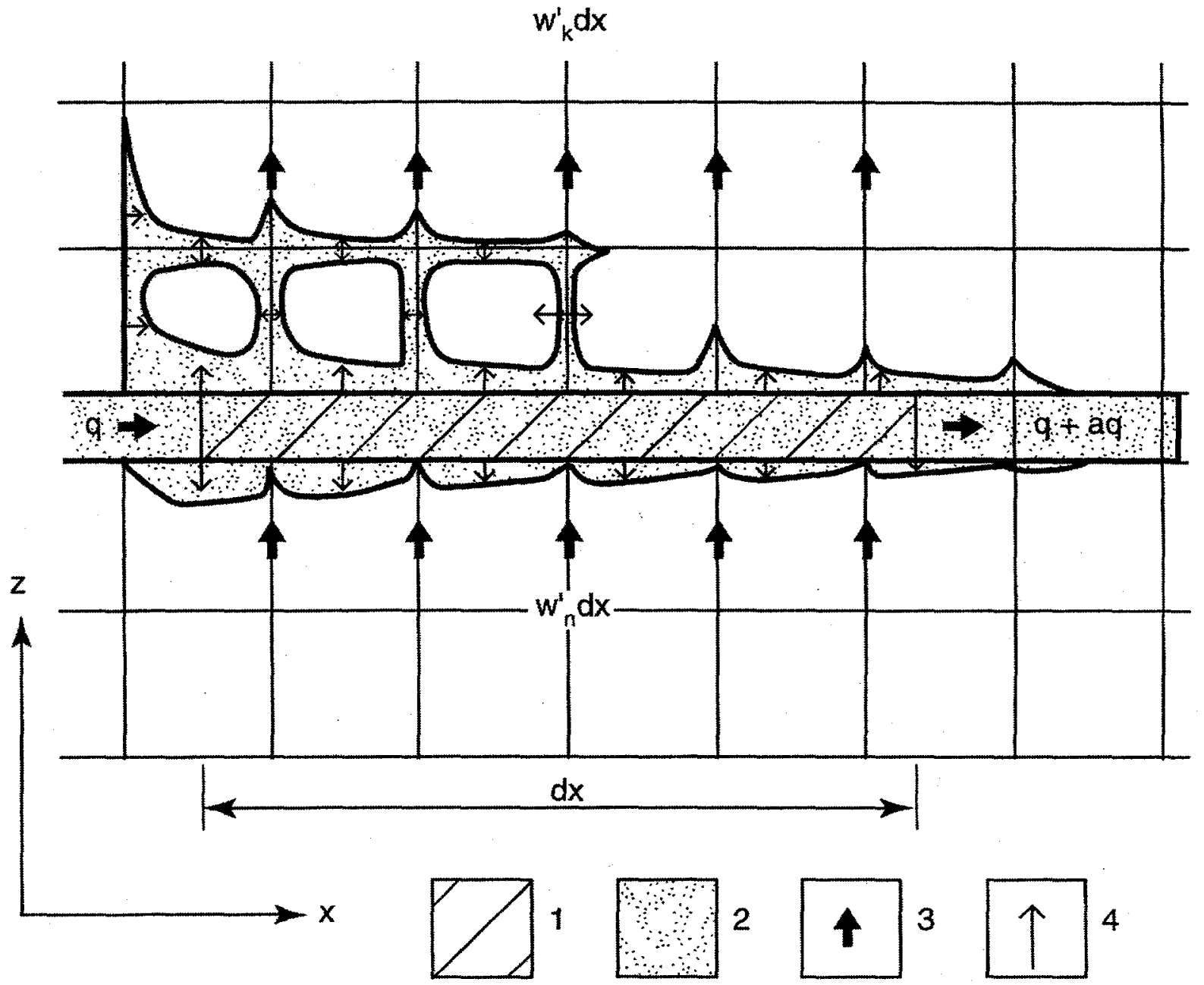

1 - cell dx of permeable karstic zone; 2 - area of contamination;

3 - convective transport direction; 4-diffusive transport direction

XBD 9803-00594.ILR

Fig. 3.2. Model of contaminant transport (three-capacity environs) 


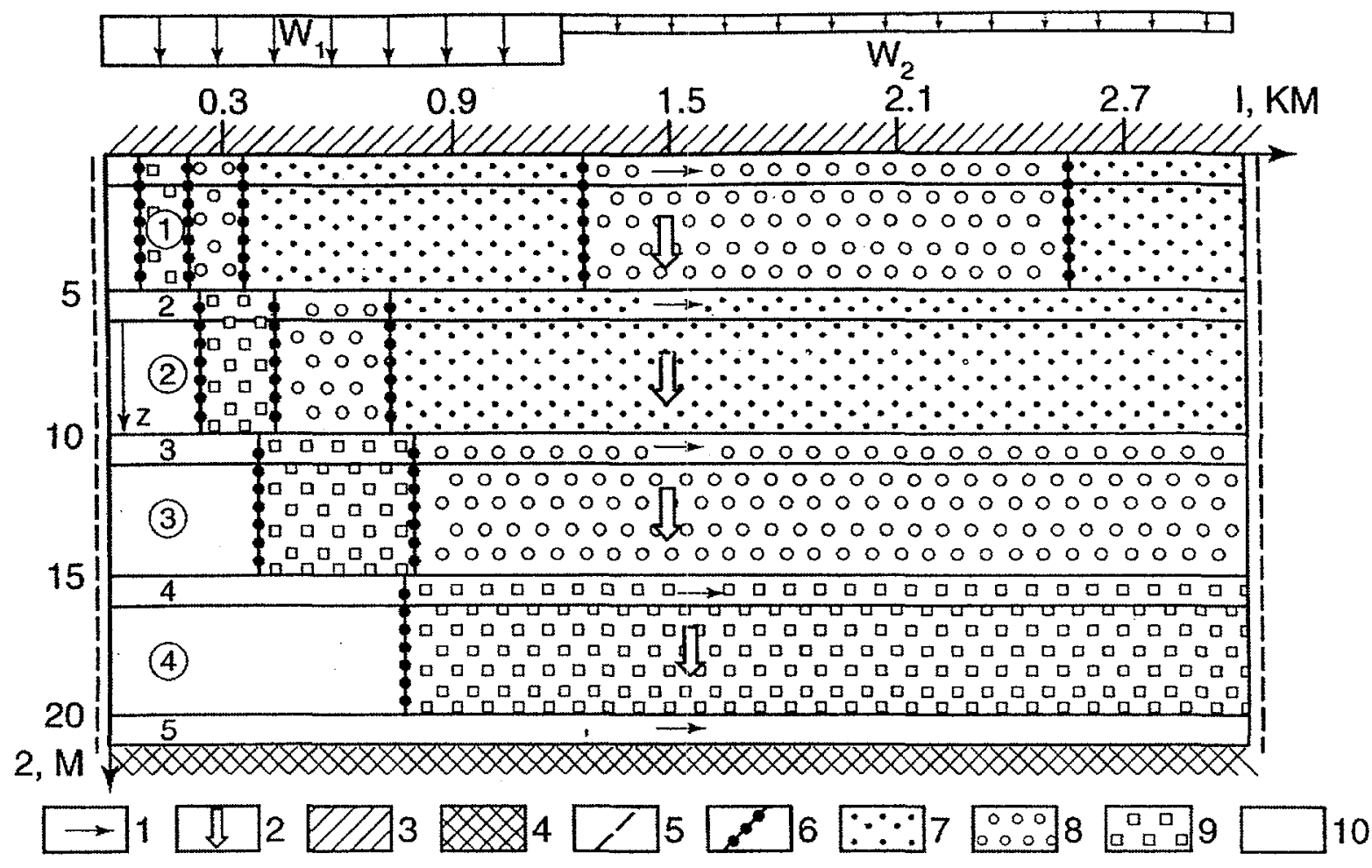

1 and 2 - direction of covection in permeable zones and low permeable layers; 3 -low permeable upper layer; 4 -impermeable rocks; 5 - boundary with constant head; 6 - boundary of different concentrations areas; $7-\mathrm{C}>0.75$; $8-\mathrm{C}=0.5-0.75 ; 9-\mathrm{C}=0.25-0.5 ; 10-\mathrm{C}<0.25$

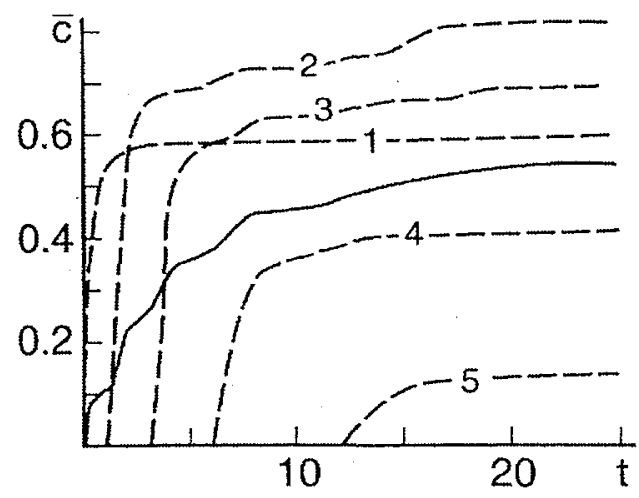

Concentration as function of time in years. (Bold line - average value of all zones; Dotted line - zones, numbered from above downwards)
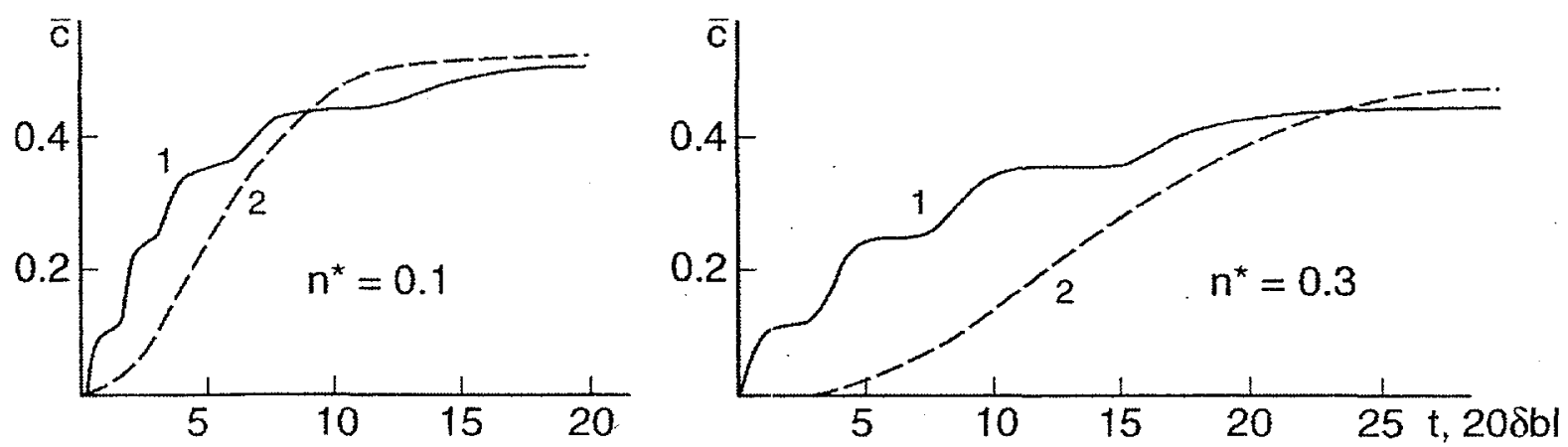

Comparison of 2-dimensional numerical and 1-dimensional analytical models

Fig. 3.3. Simulation of mass transfer in limestone aquifer 